\title{
VASCULAR DEMENTIA BY THALAMIC STRATEGIC INFARCT
}

\author{
Maria Elisa de Oliveira Lanna', Denise M. Madeira ${ }^{2,3}$, Gilberto Alves', \\ Carlos Eduardo Alves', Letice E. Valente', Jerson Laks' ${ }^{7}$ Eliasz Engelhardt ${ }^{4}$
}

Strokes in privileged sites of the cognitive and behavioral circuits constitute strategic infarct vascular dementia $(\mathrm{VaD})$ subtypes $(\mathrm{SIVaD})^{1-3}$. Among such eloquent regions the thalamic nuclei are important targets ${ }^{3-4}$. Such lesions are not common, and those involving thalamus and basal ganglia represent $4.6 \%$ of $\mathrm{VaD}$ cases $^{5-6}$. These strategic thalamic nuclei play an important integrative role and interconnects with several cortical areas (hippocampal, prefrontal). Amnesia, executive dysfunction and dysphasia are common clinical presentations, besides behavioral and psychological symptoms ${ }^{6-8}$. The thalamic nuclei may be classified in five functional classes and include associative and limbic ones. Branches from the posterior cerebral circulation supply different nuclear groups and intrathalamic tract fibers. The syndromes may be classified considering functional characteristics of the damaged nuclei and the affected vascular territories 9 . Such reports are rare in Brazil, and only two papers were published focusing subcortical structures lesions, including the thalamus.

In the present report a typical case of thalamic SIV$\mathrm{aD}$ is described, highlighting the anatomical substrates related to the clinical manifestations ${ }^{10-11}$. The study on VaD was approved by the Ethics Committee of IPUB/UFRJ and signed consent was obtained from the patient and the responsible relative.

\section{CASE}

The patient is a 54-years-old female, right handed, with 9 years of education. She was on treatment for chronic arterial hypertension, dyslipidemia and depression.

The caregiver reported that in January 2006 she woke up at night looking for her son, who was sleeping in the next room, without finding him. In the morning she presented amnesia for this episode associated to dysphasia, incoherent discourse and memory impairment. This episode was diagnosed as a stroke by the patient's general practitioner and treatment was instituted.
The patient was assessed for the first time ten months after this stroke in the outpatient ambulatory of the CDA-UFRJ. She reported memory decline and apathy in the last three months. There were no motor or sensorial impairment, and mild expression dysphasia was found on the neurological examination. The neuropsychological assessment showed Mini-Mental State Examination $(M M S E)^{12}=20 / 30$ (with impairment in orientation for time, attention and recall);Cambridge Cognitive Examination $\left(^{(C A M C O G)}\right)^{13}=66 / 107$ (performance was worse in short and long term memory [10/27], abstraction [4/8], and attention [3/7], with mild to moderate impairment in other domains, as orientation [7/10], language [25/30], praxis [8/12], perception [7/11]. An abbreviated Boston naming test $=2$ errors. The frontal functions were assessed with a modified Porteus mazes test=normal performance;Trail Making Test (TMT) part A (1min47seg) (percentile $<10)$ and part B (10min47seg) (percentile $<<10)$, both very slowed, mainly part B;semantic (animals) verbal fluency test $(V F)=9$ items $/ \mathrm{min}$. The BPSD assessment was performed with the Neuropsychiatric Inventory (NPI)=17 points (mainly depression, apathy and mild anxiety) and the Cornell Depression Scale $=8$ points (mainly anhedonia, loss of energy and pessimism). Pfeffer's Functional Activities Questionnaire $=20 / 30$. Ischaemic score of Hachinski=12 points. Clinical Dementia Rating scale - CDR=2.

The neuroimage study with brain magnetic resonance (MR) showed a thalamic infarct in the left anteromedial region (involving parts of the anteromedial and medial dorsal nuclei, and possibly the mamilothalamic tract and the ventral amygdalofugal path, vascular territory of the tuberothalamic and/or paramedian artery), and a small infarct in the right paramedian thalamus. The hippocampi showed bilateral preserved volume and signal (Fig 1). The hippocampal and posterior cingulum MR proton spectroscopy did not show significant changes. Cerebral perfusion with SPECT revealed poor fixation of the radiopharmaceutical on frontal lobes bilaterally, larger on the left side, and on temporal (anterior pole), posterior parietal and basal ganglia on left side (Fig 2). EEG was normal.

\section{DEMÊNCIA VASCULAR POR INFARTO ESTRATÉGICO TALÂMICO \\ 'Centro para Doença de Alzheimer, Instituto de Psiquiatria, UFRJ, Rio de Janeiro RJ, Brasil (CDA/IPUB/UFRJ); ${ }^{2}$ Setor de Neuroimagem, Instituto de Neu- rologia Deolindo Couto, UFRJ, Rio de Janeiro RJ, Brasil (INDC/UFRJ); ${ }^{3}$ Hospital Pró Cardíaco, Rio de Janeiro RJ, Brasil; ${ }^{4}$ Setor de Neurologia Cognitiva e do Comportamento - INDC/UFRJ.}

Received 7 December 2007, received in final form 3 March 2008. Accepted 28 March 2008. 


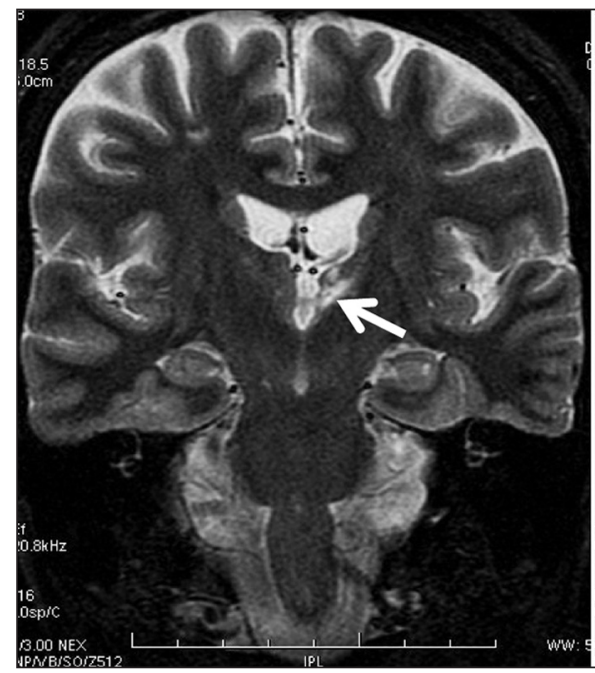

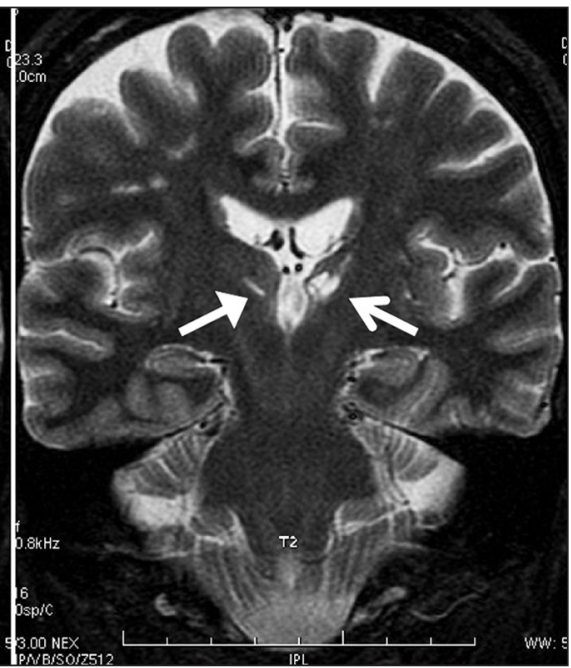

Fig 1. T2 weighted MRI: $a+b=$ coronal sections, 2 planes, show the infarct of parts of left anterior and medial dorsal nuclei (open arrows), and a small right paramedian one (closed arrow). (Courtesy of Hospital Pró(ardíaco-RJ).

\section{DISCUSSION}

Thalamic SIVaD may include several cognitive manifestations affecting memory and other functional domains depending on the involved nuclei and its connections. The main nuclei related to the mnemonic deficits are the anterior group (medial, lateral) and the medial dorsal nucleus that maintain close connections with the hippocampus, as well as with prefrontal areas, and receive their vascular supply through the tuberothalamic and/or paramedian arteries. Other case reports emphasize hippocampal related symptoms with the occurrence of lesions of the anterior thalamic nuclei, considering their connections through the mamilothalamic tract ${ }^{6-9,14}$.

The present case showed learning deficiency and short-term memory impairment (episodic and fixation, verbal recall, the visual recall being mildly affected) associated to temporal disorientation (revealed by MMSE and CAMCOG), compatible with hippocampal pathways related symptoms, and mild impairment of long-term memory. Disconnection of part of these pathways that cross the internal medullary lamina causes in addition an interruption of efferent amygdala fibers to the medial dorsal nucleus, intensifying the amnesic symptoms due to impairment of semantic and autobiographic (long-term) memory. These symptoms may also occur in cases where anterior nuclei are affected, being more severe in cases of paramedian thalamic SIVaD ${ }^{15}$.

The interruption of thalamic-frontal connections (pertaining to the basal ganglia-thalamus-prefrontal circuits) is related to executive dysfunction symptoms as revealed by the TMT, particularly part B, with very slow performance, impulsivity, as well as sequencing and inattention errors. Attention impairment was also expressive (shown by MMSE and CAMCOG). There was also poor spontaneous speech and low VF performance related to executive dysfunction.
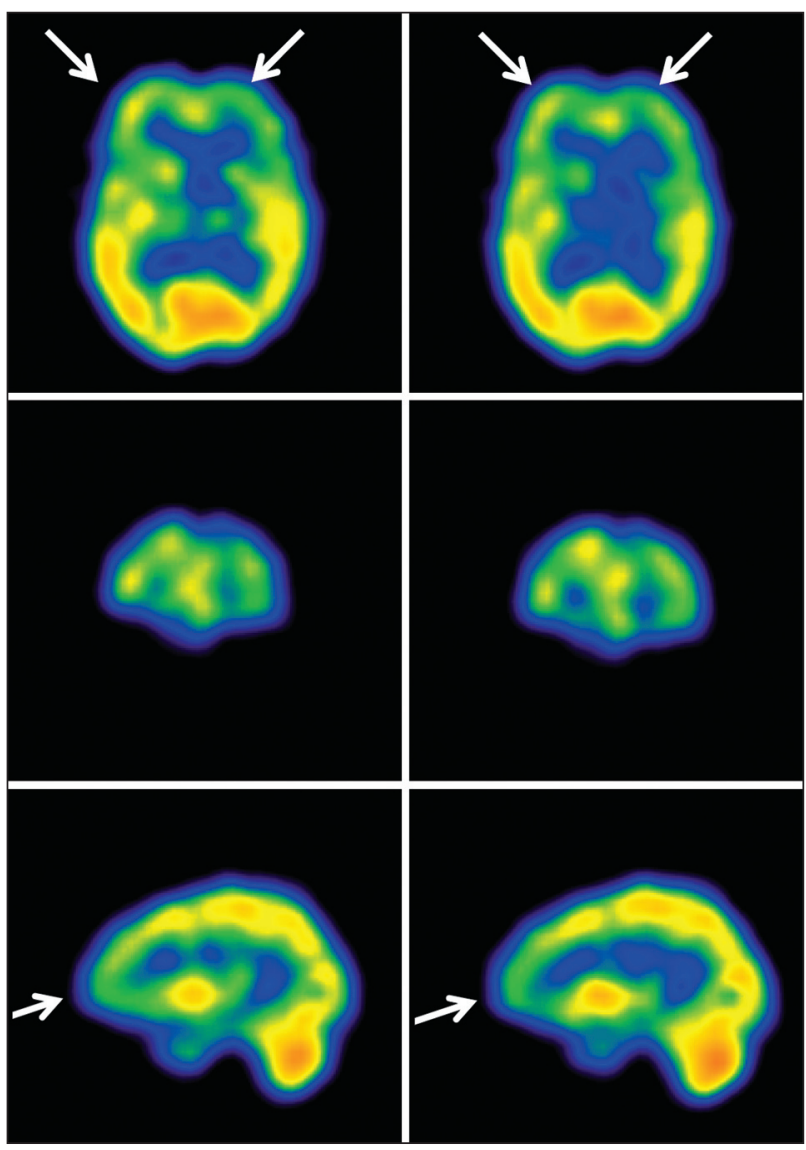

Fig 2. Cerebral perfusion with SPECT: frontal hypoperfusion, with emphasis on the left side (arrows);temporal and posterior parietal hypoperfusion can also be seen. (Courtesy of Centro Diagnóstico Guanabara-RJ).

A low performance in items related to abstract thinking was also found ${ }^{10,16}$. There was additionally mild motor transcortical aphasia, with preserved repetition, consistent with the reports found in the literature on speech disorders in connection with left anterior nucleus infarct ${ }^{7,11}$. 
Mood disorder with depression and severe apathy, as revealed by NPI and Cornell are frequent symptoms of limbic circuit lesions as seen in the present case ${ }^{9,17}$. Pfeffer's functional scale indicated moderate dependency. CDR characterized moderate dementia, stable since the stroke occurrence. MRI clearly showed the lesion, particularly the T2 weighted images, a peculiarity observed in thalamic infarcts ${ }^{18-19}$. SPECT showed hypoperfusion in the frontal region, larger on the left side which can be considered as a probable consequence of thalamic-frontal disconnection ${ }^{6}$.

The correlation of clinical, neuroimage, and chronological findings allowed for the diagnosis of a probable thalamic SIVaD, according to NINDS-AIREN criteria ${ }^{20-21}$. Strategic infarcts show a peculiar characteristic of causing dementia in an acute way, and of remaining permanently once established at the time of the ischemic stroke ${ }^{6}$. Well restricted thalamic lesions show this aspect in a clear fashion, as the sole cause for the appearance of the dementia picture, as illustrated by this case.

In conclusion, the present case represents a typical SIVaD, with memory impairment, attention deficit and executive dysfunction as the main symptoms. These manifestations are clearly related to an anteromedian region thalamic lesion, as shown by MRI, and of thalamic-frontal disconnection, as shown by SPECT images.

\section{REFERENCES}

1. Román GC. Facts, myths, and controversies in vascular dementia. J Neurol Sci 2004;226:49-52.

2. Engelhardt E, Laks J, Cavalcanti JLS, Moreira DM, Madalen C. Demência vascular. Rev Bras Neurol 2004;40:5-25

3. Engelhardt E, Moreira DM, Laks J, et al. Demência vascular: os grandes subtipos clínico-patológicos isquêmicos. Rev Bras Neurol 2006;42:5-15.
4. Mok V, Chang C, Wong A, et al. Neuroimaging determinants of cognitive performances in stroke associated with small vessel disease. J Neuroimaging 2005;15:129-137.

5. Wetterling T, Kanitz RD, Borgis KJ. Comparison of different diagnostic criteria for vascular dementia (ADDTC, DSM-IV, ICD-10, NINDSAIREN). Stroke 1996;27:30-36.

6. Szirmai I, Vastagh I, Szombathelyi E, Kamondi A. Strategic infarcts of the thalamus in vascular dementia. J Neurol Sci 2002;203-4:91-97.

7. Carrera E, Michel P, Bogousslavsky J. Anteromedian, central, and posterolateral infarcts of the thalamus: three variant types. Stroke 2004; 35:2826-2831.

8. Mitchell AS, Dalrymple-Alford JC. Lateral and anterior thalamic lesions impair independent memory systems. Learn Mem 2006;13:388-396.

9. Schmahmann JD. Vascular syndromes of the thalamus. Stroke 2003;34: 2264-2278.

10. Radanovic M, Azambuja M, Mansur LL, Porto CS, Scaff M. Thalamus and language: interface with attention, memory and executive functions. Arq Neuropsiquiatr 2003;61:34-42.

11. Radanovic M, Mansur LL, Azambuja MJ, Porto CS, Scaff M. Contribution to the evaluation of language disturbances in subcortical lesions: a pilot study. Arq Neuropsiquiatr 2004;62:51-57

12. Folstein MF, Folstein SE, McHugh PR. Mini-mental state: a practical method for grading cognitive state of patients for the clinician. J Psychiat Res 1975;12:189-198.

13. Roth M, Tym E, Mountjoy CQ, et al. A standardised instrument for the diagnosis of mental disorder in the elderly with special reference to the early detection of dementia. Br J Psychiatry 1986;149:698-709.

14. Pérez-Lázaro C, Santos S, Garcés-Redondo M, et al. Ictus amnésico por infarto hipocámpico. Rev Neurol 2005;41:27-30.

15. Markowitsch HJ. Diencephalic amnesia: a reorientation towards tract? Brain Res Rev 1998;13:351-370.

16. Brucki SMD, Rocha MSG. Category fluency test: effects of age, gender and education on total scores, clustering and switching in Brazilian Portuguese-speaking subjects. Braz J Med Biol Res 2004;37:1771-1777.

17. Yakolev PL, Locke S. Limbic nuclei of thalamus and connections of limbic cortex. Arch Neurol 1961;15:34-71.

18. Swartz RH, Black SE. Anterior-medial thalamic lesions in dementia: frequent, and volume dependently associated with sudden cognitive decline. J Neurol Neurosurg Psychiatry 2006;77:1307-1312.

19. Leite AJB, van Straaten ECW, Scheltens P, et al. Thalamic lesions in vascular dementia: low sensitivity of fluid-attenuated inversion recovery (FLAIR) imaging. Stroke 2004;35:415-419.

20. Román GC, Tatemichi TK, Cummings JL, et al. Vascular dementia: diagnostic criteria for research studies: report of the NINDS-AIREN International Workshop. Neurology 1993;43:250-260.

21. Rasquin SMC, Lodder J, Verhey FRJ. The effect of different diagnostic criteria on the prevalence and incidence of post-stroke dementia. Neuroepidemiology 2005;24:189-195. 